\title{
Routine handling of propofol prevents contamina- tion as effectively as does strict adherence to the manufacturer's recommendations
}

\author{
[Le maniement d'usage du propofol prévient la contamination aussi effectivement
} que la stricte adhésion aux recommandations du fabricant]

Ingo H. Lorenz MD, ${ }^{*}$ Christian Kolbitsch MD DEAA, ${ }^{*}$ Cornelia Lass-Flörl MD, $†$ Irene Gritznig MD, ${ }^{*}$ Burkard Vollert MD, ${ }^{*}$ Werner Lingnau MD EDIC, ${ }^{*}$ Patrizia L. Moser MD, $\ddagger$ Arnulf Benzer MD DEAA*

Purpose: Propofol is a potential vector of infection, because it contains no preservative. Thus, the manufacturer's specific recommendations for preparing injections or infusions go beyond the guidelines commonly used in our operating rooms for preparing other iv drugs. The purpose of the present study was to determine whether in the daily routine of an operating theatre a modified propofol handling technique can prevent contamination as effectively as do the manufacturer's handling recommendations.

Methods: A total of 160 consecutive neurosurgical patients were allocated to either Group I (manufacturer's handling recommendations: i.e., I) disinfecting propofol vials and ampoules before filling syringes; 2) replacing empty syringes; 3 ) discarding all material at the end of surgery); or Group II (modified propofol handling protocol: i.e., I) refilling empty syringes; 2 ) renewing only the infusion line to the patient).

Results: Total contamination rates were comparable in both groups (Group I: I4/I60 (8.75\%), Group II: I3/I60 (8.13\%) $\left(\chi^{2}=0.074 ; P=0.96\right)$. Frequency of contamination was not different between groups; either in sample I taken at the beginning of the procedure, (Group I: 5/80 (6.25\%) vs Group II: 6/80 (7.5\%); $\left.\chi^{2}=0.098 ; P=0.76\right)$ or in sample 2, taken at the end, (Group I: 9/80 ( I I.25\%) vs Group II: 7/80 (8.75\%); $\left.\chi^{2}=0.278 ; P=0.598\right)$.

Conclusion: We conclude that in the daily routine of the operating theatre following a modified propofol handling protocol prevents contamination of propofol syringes as effectively as does adhering to the manufacturer's specific handling recommendations. However, neither of the tested guidelines completely prevented contamination.
Objectif: Le propofol, ne contenant aucun agent de conservation, est un vecteur potentiel d'infection. C'est pourquoi les recommandations spécifiques du fabricant au sujet de la préparation d'injections ou de perfusions vont au delà des directives habituellement suivies dans nos salles d'opération pour la préparation d'autres médicaments intraveineux. Nous avons voulu déterminer si, en modifiant le maniement du propofol en salle d'opération, nous pouvions prévenir la contamination aussi efficacement qu'en suivant à la lettre les recommandations du fabricant.

Méthode: Un total de 160 patients successifs de neurochirurgie ont été répartis en deux groupes. Pour le Groupe I on a suivi les recommandations du fabricant en I) désinfectant les flacons et les ampoules de propofol avant de remplir les seringues; 2) remplaçant les seringues vides; 3) jetant tout le matériel à la fin de l'intervention chirurgicale. Pour le Groupe II, on a modifié le maniement du propofol en I) remplissant les seringues vides et 2) en renouvelant seulement les tubulures à perfusion des patients.

Résultats : Les taux de contamination totale sont comparables : 14/160 (8,75 \%) dans le Groupe l et 13/160 (8, 13\%) dans le Groupe $\|\left(\chi^{2}=0,074 ; P=0,96\right)$. La fréquence de contamination ne differe pas d'un groupe à l'autre, pour l'échantillon I prélevé au début de l'opération (Groupe I : 5/80 (6,25 \%) vs Groupe II : 6/80 (7,5 \%); $\left.\chi^{2}=0,098 ; P=0,76\right)$ ou l'échantillon 2 à la fin (Groupe I: 9/80 ( I 1,25 \%)vs Groupe II : 7/80 (8,75\%); $\left.\chi^{2}=0,278 ; P=0,598\right)$.

Conclusion : L'usage quotidien d'un protocole modifié de maniement du propofol en salle d'opération prévient aussi efficacement la contamination des seringues que l'adhésion aux recommandations spécifiques du fabricant. Aucune des directives testées n'a permis d'éliminer complètement la contamination.

From the Departments of Anaesthesia and Intensive Care Medicine, ${ }^{*}$ Hygiene and Social Medicine, $†$ and Pathology, $\ddagger$ University of Innsbruck, Innsbruck, Austria.

Address correspondence to: Dr. Christian Kolbitsch, Department of Anaesthesia and Intensive Care Medicine, University of Innsbruck, Anichstr. 35, A-6020 Innsbruck, Austria. Phone: +43-(0) 512-504-2400; Fax: +43-(0) 512-504-2450; E-mail:

christian.kolbitsch@uibk.ac.at

Financial support: none

Accepted for publication July 16, 2001.

Second revision accepted December 17, 2001. 
$\mathrm{P}$ ERIOPERATIVE infectious complications have been attributed to propofol as a possible causative agent ${ }^{1-4}$ because of suspected lapses in aseptic technique when handling the drug. ${ }^{1,5}$ The absence of preservatives in the propofol preparation may support microbial growth. $^{6-14}$ Admixture of thiopentone, ${ }^{15}$ lidocaine ${ }^{16-19}$ or disodium edetate $^{20}$ diminishes microbial growth in propofol, although microbial destruction is not achieved. Because of this risk, the manufacturer's specific recommendations (Fresenius Kabi Pharmaceutical. Propofol "Fresenius" 1\% package insert 2001; Graz, Austria) for preparing the drug for injection or infusion go beyond the aseptic precautions commonly used in our operating rooms for preparing other $i v$ drugs.

We compared the frequency of propofol contamination when preparing drug solutions in a routine operating theatre setting when following either routine aseptic precautions or the manufacturer's specific handling recommendations.

\section{Material and methods}

The study was approved by our Institutional Review Board and enrolled 160 consecutive neurosurgical patients scheduled for lumbar hemilaminectomy. All patients had given their written informed consent on the day prior to surgery. Following induction of anesthesia propofol infusion was started.

The patients were randomly allocated to either Group I (e.g., propofol handling strictly according to the manufacturer's specific recommendations) or Group II (e.g., modified propofol handling protocol based on routine aseptic precautions).

In both groups (Group I, Group II) the following study procedures were identical and consisted of:

preparing the propofol infusions immediately prior to administration; wearing sterile single-use gloves when taking the samples (one and two) for microbial analysis (detailed below); taking sample l (i.e., $5 \mathrm{~mL}$ propofol, which was injected in a sterile test tube) from the distal end of the infusion line before connecting it to the patient's iv tubing at the beginning of the anesthetic procedure; taking sample 2 (i.e., $5 \mathrm{~mL}$ propofol, which was injected in a sterile test tube) at the end of surgery, namely from the infusion line which was disinfected with an isopropyl alcohol $(70 \%)$ swab approximately $50 \mathrm{~cm}$ proximal to the patient's iv tubing before cutting it with a sterile pair of scissors.

The following study procedures differed between the two groups:

\section{Group I}

In strict accordance with the manufacturer's specific handling recommendations, the uncapped rubber stopper of the propofol vials $(50 \mathrm{~mL})$ was disinfected with isopropyl alcohol (70\%), and the neck of the propofol ampoules $(20 \mathrm{~mL})$ was broken while held with an alcohol swab before filling the syringes. Furthermore, when a syringe was empty it was replaced with a new, freshly prepared one. In all cases, administration was completed before the six-hour time limit. All material was discarded at the end of surgery (Figure 1).

\section{Group II}

The modified propofol handling protocol was based on routine aseptic precautions.

Recommendations for preparing and handling drugs at our institution do not prescribe disinfection of propofol vials or ampoules before filling a syringe. Furthermore, in contrast to

Group I, refilling of propofol syringes is an accepted practice.

Refilling was effected by turning a three-way stopcock so that it was possible to draw propofol from a propofol vial $(50 \mathrm{~mL})$ connected to the stopcock by an infusion line. The three-way stopcock was located between the perfusor syringe and the infusion line to the patient.

At the end of each operation the same syringe was refilled and used for the next patient. Only the infusion line between the stopcock and the patient was changed (Figure 2).

\section{Microbial analysis}

Four subsamples (each $0.1 \mathrm{~mL}$ ) were taken from samples 1 and 2 for further examination with all work conducted under a laminar-air-flow hood (all plates and broth from Becton Dickinson Co, Cockeysville, Maryland, USA).

Subsample 1 was cultured on Columbia blood-agar plates in order to test for aerobically culturable microorganisms. Subsample 2 was cultured on anerobic blood-agar plates followed by incubation at $37^{\circ} \mathrm{C}$ for $48 \mathrm{hr}$ in order to test for anerobic microorganisms.

Subsample 3 was cultured on Saboraud glucoseagar with chloramphenicol supplement and incubated at $30^{\circ} \mathrm{C}$ for four days in order to cultivate yeasts and moulds.

Subsample 4 was cultured on thioglycolate and Saboraud broths in order to enrich the sample.

Differential analysis of the microorganisms was performed using morphological and serological criteria. The morphological criteria applied were shape, size, surface and margin characteristics of the colonies and, when indicated, gram staining. The serological criteria 


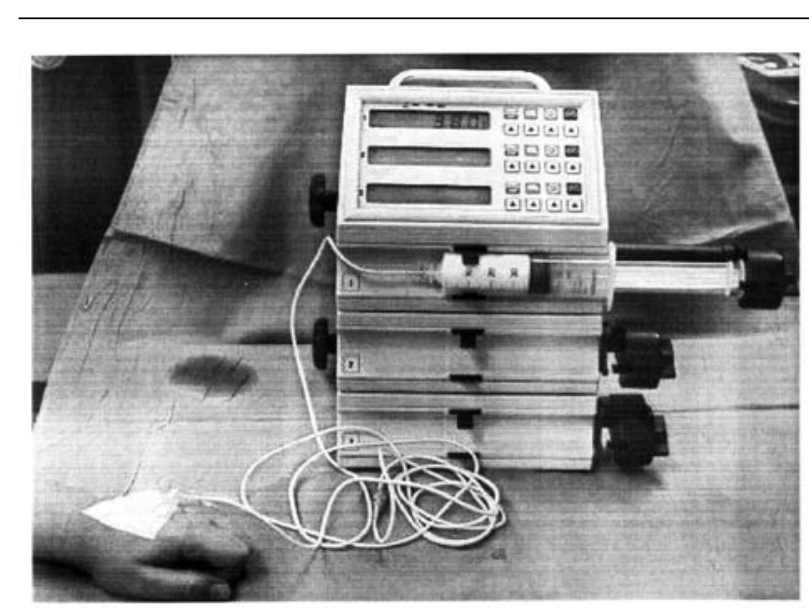

FIGURE 1 Depicts propofol infusion prepared in strict accordance with the manufacturer's specific handling recommendations (Group I). The empty syringe was replaced with a freshly prepared new one. All material was discarded at the end of surgery.

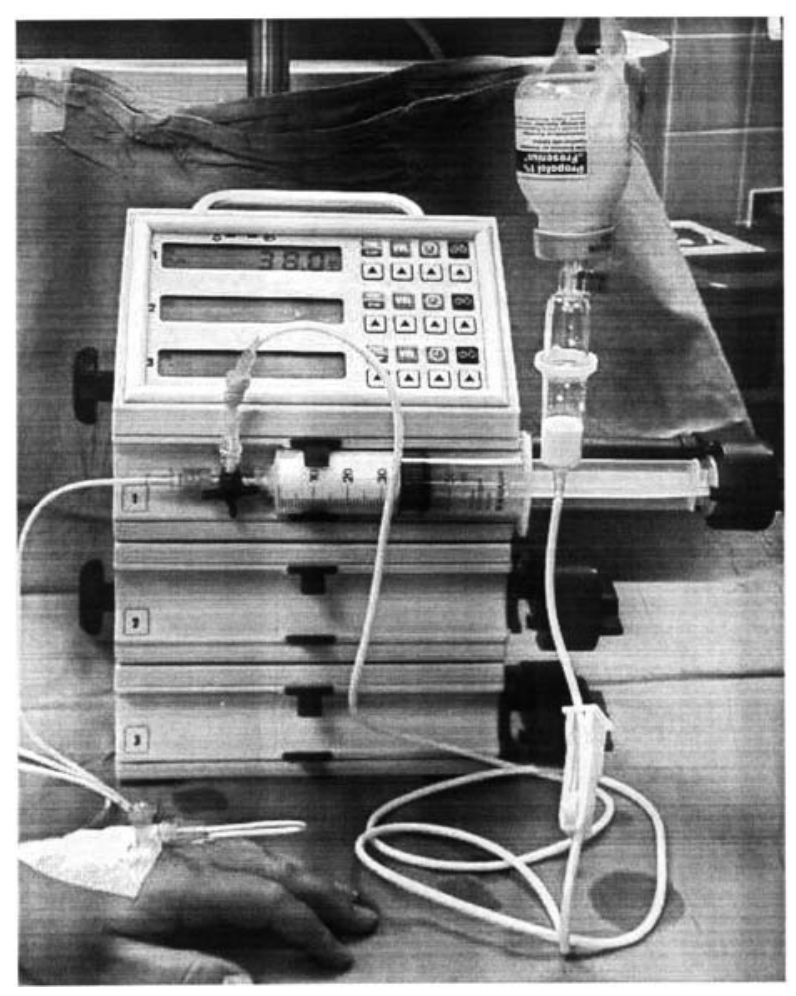

FIGURE 2 Depicts propofol infusion prepared with routine aseptic precautions (Group II). Refilling was effected by turning a three-way stopcock so that it was possible to draw propofol from a propofol vial $(50 \mathrm{~mL})$ connected to the stopcock by an infusion line. At the end of each operation the same syringe was refilled and used for the next patient. Only the infusion line between the stopcock and the patient was changed.
TABLE I

\begin{tabular}{lllll}
\hline & \multicolumn{2}{c}{ Group I } & \multicolumn{2}{c}{ Group II } \\
& $\begin{array}{l}\text { Sample 1 } \\
(n=80)\end{array}$ & $\begin{array}{l}\text { Sample 2 } \\
(n=80)\end{array}$ & $\begin{array}{l}\text { Sample 1 } \\
(n=80)\end{array}$ & $\begin{array}{l}\text { Sample 2 } \\
(n=80)\end{array}$ \\
\hline Staph epidermidis & $4(2)^{\mathrm{a}}$ & $8(3)$ & $6(3)$ & $7(3)$ \\
Spore-bearing bacilli & $1(1)$ & 1 & - & - \\
Fungi & - & - & - & - \\
\hline
\end{tabular}

Contamination in Group I (manufacturer's specific recommendations) and in Group II (institutional routine aseptic recommendations). ${ }^{a}=$ numbers in parentheses indicate number of patients with contamination in both samples.

TABLE II

\begin{tabular}{lllllll}
\hline Frequency & 0 & 1 & 2 & 3 & 4 & 5 \\
\hline Group I & 20 & 34 & 18 & 4 & 2 & 2 \\
Group II & 10 & 31 & 25 & 12 & 1 & 1 \\
\hline
\end{tabular}

Frequency of intraoperative replacement (Group I) or refilling (Group II) of propofol syringes.

were hemolytic behaviour, pigment formation and, in the case of staphylococci, the presence or absence of plasma coagulase (Pastorex Staph Plus, Sanofi Pasteur Diagnostics, Chaska, MN, USA).

Aerobic bacilli microscopically found as gram positive rods where further analyzed to see if they produce catalase and form spores. Further classification of these aerobic spore-forming bacilli was, however, not performed.

Some samples from both groups were screened for occult blood (Sangur Test ${ }^{\circledR}$, Boehringer Mannheim, Vienna, Austria).

\section{Statistical analysis}

Data are summarized as mean or proportions, as appropriate. We used a two-tailed t test for independent samples to analyze the amount of drug used in each group and to compare the duration of surgical procedures. We further analyzed the frequency of syringe replacement or refilling and compared the incidence of microbial contamination of samples using the Chi square test. We report a Chi square value, and a $P$ $<0.05$ was considered statistically significant. Power analysis (for the Chi square test) showed that, for a power of $>0.8$ an alpha error of 0.05 and a $\mathrm{pl}=P(\mathrm{X}<\mathrm{Y})$ of $\geq 0.08$, the number of patients needed to reject the null hypothesis was 80 .

\section{Results}

Total contamination of samples (at the beginning and at the end of surgery) was similar in both groups 
Group I: 14/160 (8.75\%), Group II: 13/160 (8.13\%; $\chi^{2}=0.074 ; P=0.96$; Table I). Frequency of contamination was not different between groups either in sample 1 (Group I: 5/80 (6.25\%) vs Group II: 6/80 $(7.5 \%) ; \chi^{2}=0.098 ; P=0.76$ ) or in sample 2 (Group I: $9 / 80$ (11.25\%) vs Group II: $7 / 80(8.75 \%) ; \chi^{2}=0.278$; $P=0.598$; Table I). Contamination of both samples in the same patient was found with the same frequency $3 / 80(3.75 \%)$ in both groups (Table I).

The contaminating microorganisms were Staphylococcus epidermidis ( 25 cases) and spore-bearing bacilli (two cases), but none of the samples showed fungal contamination.

The mean amount of propofol needed per procedure (mean \pm SD; Group I: $633.3 \pm 25.8 \mathrm{mg}$ vs Group II: $574.8 \pm 26.1 \mathrm{mg}$; NS) and the mean duration of the procedure (Group I: $75 \pm 32 \mathrm{~min} v s$ Group II: 69 $\pm 22 \mathrm{~min}$; NS) were comparable in both groups.

Furthermore, intraoperative replacement (Group I) or refilling (Group II) of the empty propofol syringe occurred at the same frequency in both groups (Group I: $n=100$ and Group II: $n=126 ; \chi^{2}=9.278$; $P=0.099$; Table II).

The duration of the procedure, total amount of propofol needed (per procedure) and the 14 anesthesiologists involved exerted an identical influence on the frequency of contamination in both groups. No perioperative infectious complications were observed in any of the patients enrolled in the study.

\section{Discussion}

Perioperative infections may increase morbidity and mortality, the number of days in hospital and consequently the cost to the public health system. ${ }^{21-24}$

In this context, propofol handling can be a pivotal factor as the drug is considered a highly potent vector of infection. The results of our study suggest that, in the daily routine of the operating theatre, a modified propofol handling technique based on routine aseptic precautions prevents the contamination of propofol syringes as effectively as does strict adherence to the manufacturer's specific handling recommendations. However, neither of the handling guidelines completely prevented contamination.

Comparing the protocol for handling propofol commonly used in our operating rooms with the manufacturer's recommendations puts our study at the forefront of potential controversy, especially as far as ethics are concerned. The protocol followed in Group II subjects patients to a practice that is in opposition to the recommendations of both the American Society of Anesthesiologists ${ }^{25}$ and the Centers for Disease Control. ${ }^{26}$
Ethical considerations would have been justified and would have made a study like ours impossible had the existing recommendations been validated. Since this is not the case, we felt there was an obligation to subject this question to scientific study by testing the recommendations against routine practice at our institution.

The major anticipated concern is that in Group II the syringe was refilled and only the infusion line was renewed for each of the consecutive patients in that theatre. Theoretically, there are at least two possible risks for contamination under these circumstances, namely the refilling itself and the potential blood reflux from the patient's $i v$ tubing.

Refilling from a propofol vial via an infusion line after turning a three-way stopcock can be considered a closed system with a potentially lower frequency of microbial contamination than with an open system, such as when replacing an empty propofol syringe (Group I). The contamination observed in our study may be, in part, attributed to refilling or replacing syringes.

Reflux of blood from the patient's iv tubing, which is also a potential source of contamination, was neither observed macroscopically in any of the cases nor found when screening some of the samples for occult blood. Any observed blood reflux, however, would have caused the syringe to be discarded at the end of surgery (in Group II).

When reviewing the literature on which the manufacturer's specific handling recommendations are based, a considerable number of studies were found to have been conducted in the laboratory. In this context, Zachner et al. found less contamination of propofol ampoules which had been swabbed with a solution of Staphylococcus epidermidis, when they were wiped with alcohol prior to opening. ${ }^{27}$ Although it is not common practice to swab propofol ampoules in solutions containing bacteria, it should be remembered that routine anesthesia practice has repeatedly been accused of being a potential factor in the contamination of drugs. ${ }^{28-31}$ The risk of contaminating propofol syringes would be expected to increase with the number of personnel involved in handling the drug. Although contamination occurred in our study despite close attention by the anesthesiologist to aseptic technique, analysis of the frequency of contamination could not identify inappropriate aseptic practices used by a specific anesthesiologist.

Several other laboratory studies have reported a $0 \%$ incidence of contamination when the manufacturer's recommendations are followed meticulously. ${ }^{32-34}$ The most probable explanation for this discrepancy is that a propofol syringe handled routinely in an operating theatre is naturally at a much greater risk of contami- 
nation than is a propofol syringe kept under sterile conditions in the laboratory. Accordingly, contamination frequencies comparable to those of the present study have been reported previously, not only for the anesthesia workplace ${ }^{35,36}$ but also for intensive care units ${ }^{37}$ during the routine use of propofol.

Thus, we assume that the contamination rate found in this study despite strict adherence to the manufacturer's recommendations is a risk that probably cannot be eliminated as long as the conditions in an operating theatre are different from those in a laboratory.

In summary, we found that a propofol handling technique based on routine aseptic recommendations in use at our institution prevents contamination of propofol syringes as effectively as does adherence to the manufacturer's specific handling recommendations. However, neither of the tested guidelines completely prevents contamination in clinical practice.

\section{References}

1 Bennett SN, McNeil MM, Bland LA, et al. Postoperative infections traced to contamination of an intravenous anesthetic, propofol. N Engl J Med 1995; 333: 147-54.

2 Carr S, Waterman S, Rutherford G, et al. Postsurgical infections associated with an extrinsically contaminated intravenous anesthetic agent-California, Illinois, Maine, and Michigan. MMWR 1990; 39: 426-33.

3 Bach A, Motsch J. Infectious risks associated with the use of propofol. Acta Anaesthesiol Scand 1996; 40: 1189-96.

4 McNeil MM, Lasker BA, Lott TJ, Jarvis WR. Postsurgical Candida albicans infections associated with an extrinsically contaminated intravenous anesthetic agent. J Clin Microbiol 1999; 37: 1398-403.

5 Veber B, Gachot B, Bedos JP, Wolff M. Severe sepsis after intravenous injection of contaminated propofol (Letter). Anesthesiology 1994; 80: 712-3.

6 Arduino MJ, Bland LA, McAllister SK, et al. Microbial growth and endotoxin production in the intravenous anesthetic propofol. Infect Control Hosp Epidemiol 1991; 12: 535-9.

7 Kuehnert MJ, Webb RM, Jochimsen EM, et al. Staphylococcus aureus bloodstream infections among patients undergoing electroconvulsive therapy traced to breaks in infection control and possible extrinsic contamination by propofol. Anesth Analg 1997; 85: 420-5.

8 Berry CB, Gillespie T, Hood J, Scott NB. Growth of micro-organisms in solutions of intravenous anaesthetic agents. Anaesthesia 1993; 48: 30-2.

9 Sosis MB, Braverman B, Villaflor E. Propofol, but not thiopental, supports the growth of Candida albicans. Anesth Analg 1995; 81: 132-4.
10 Sosis MB, Braverman B. Growth of Staphylococcus aureus in four intravenous anesthetics. Anesth Analg 1993; 77: 766-8.

11 Tessler M, Dascal A, Gioseffini S, Miller M, Mendelson J. Growth curves of Staphylococcus aureus, Candida albicans, and Moraxella osloensis in propofol and other media. Can J Anaesth 1992; 39: 509-11.

12 Daily MJ, Dickey JB, Packo KH. Endogenous Candida endophthalmitis after intravenous anesthesia with propofol. Arch Ophthalmol 1991; 109: 1081-4.

13 Graystone $S$, Wells MF, Farrell DJ. Do intensive care drug infusions support microbial growth? Anaesth Intensive Care 1997; 25: 640-2.

14 Farrington M, McGinnes J, Matthews I, Park GR. Do infusions of midazolam and propofol pose an infection risk to critically ill patients? Br J Anaesth 1994; 72: 415-7.

15 Crowther J, Hrazdil J, Jolly DT, Galbraith JC, Greacen $M$, Grace M. Growth of microorganisms in propofol, thiopental, and a 1:1 mixture of propofol and thiopental. Anesth Analg 1996; 82: 475-8.

16 Gajraj RJ, Hodson MJ, Gillespie JA, Kenny GNC, Scott $N B$. Antibacterial activity of lidocaine in mixtures with Diprivan. Br J Anaesth 1998; 81: 444-8.

17 Wachowski I, Jolly DT, Hrazdil J, Galbraith JC, Greacen $M$, Clanachan AS. The growth of microorganisms in propofol and mixtures of propofol and lidocaine. Anesth Analg 1999; 88: 209-12.

18 Vidovich MI, Peterson LR, Wong HY. The effect of lidocaine on bacterial growth in propofol. Anesth Analg 1999; 88: 936-8.

19 Sakuragi T, Yanagisawa K, Shirai $\Upsilon$, Dan K. Growth of Escherichia coli in propofol, lidocaine, and mixtures of propofol and lidocaine. Acta Anaesthesiol Scand 1999; 43: 476-9.

20 Hart B. 'Diprivan': a change of formulation (Letter). Eur J Anaesthesiol 2000; 17: 71-3.

21 Culver DH, Horan TC, Gaynes RP, et al., National Nosocomial Infections Surveillance System. Surgical wound infection rates by wound class, operative procedure, and patient risk index. Am J Med 1991; 91(suppl 3B): 152S-7S.

22 Haley RW, Culver DH, Morgan WM, White JW, Emori $T G$, Hooton TM. Identifying patients at high risk of surgical wound infection. A simple multivariate index of patient susceptibility and wound contamination. Am J Epidemiol 1985; 121: 206-15.

23 Haley RW, Culver DH, White JW, Morgan WM, Emori $T G$. The nationwide nosocomial infection rate. A new need for vital statistics. Am J Epidemiol 1985; 121: $159-67$.

24 Nichols RL, Smith JW. Bacterial contamination of an anesthetic agent (Editorial). N Engl J Med 1995; 333: 184-5. 
25 Hughes $S$. American Society of Anesthesiologists (ASA): Recommendations for Infection Control for the Practice of Anesthesiology, (2 $2^{\text {nd }} \mathrm{ed}$.).

http://www.asahq.org/ProfInfo/Infection/Infection_ TOC.html 2001.

26 Pearson ML. Centers for Disease Control (CDC):

Guideline for prevention of intravascular device-related infections. Part 1. Intravascular device-related infections: an overview. The Hospital Infection Control Practices Advisory Committee. Am J Infect Control 1996; 24: 262-77.

27 Zacher AN, Zornow MH, Evans G. Drug contamination from opening glass ampules. Anesthesiology 1991; 75: 893-5.

28 Kempen PM, Sulkowski E, Sawyer SA. Glass ampules and associated hazards. Crit Care Med 1989; 17: 812-3.

29 Rosenberg AD, Bernstein DB, Bernstein RL, Skovron $M L$, Ramanathan S, Turndorf $H$. Accidental needlesticks: do anesthesiologists practice proper infection control precautions? Am J Anesthesiol 1995; 22: 125-32.

30 Lessard MR, Trépanier CA, Gourdean M, Denault PH. A microbiological study of the contamination of the syringes used in anaesthesia practice. Can J Anaesth 1988; 35: 567-9.

31 Magee L, Godsiff L, Matthews I, Farrington M, Park $G R$. Anaesthetic drugs and bacterial contamination. Eur J Anaesthesiol 1995; 12(Suppl. 12): 41-3.

32 Warwick JP, Blake D. Drawing up propofol (Letter). Anaesthesia 1994; 49: 172.

33 McLeod GA, Pace N, Inglis MD. Bacterial growth in propofol (Letter). Br J Anaesthesia 1991; 67: 665-6.

34 Downs GJ, Haley PR, Parent JB. Propofol: can a single ampule be used for multiple patients? (Letter). Anesthesiology 1991; 74: 1156-7.

35 Bach A, Motsch J, Schmidt H, et al. In-use contamination of propofol. A clinical study. Eur J Anaesthesiol 1997; 14: 178-83.

36 McHugh GJ, Roper GM. Propofol emulsion and bacterial contamination. Can J Anaesth 1995; 42: 801-4.

37 Webb SAR, Roberts B, Breheny FX, Golledge CL, Cameron PD, Van Heerden PV. Contamination of propofol infusions in the intensive care unit: incidence and clinical significance. Anaesth Intensive Care 1998; 26: 162-4. 